\title{
Sistem Informasi Kursus Setir Mobil Berbasis Web Pada LPK Citra Indotech Jaya Purwokerto
}

\author{
Sunanto $^{1}$, Ina Maryani ${ }^{2}$, Gresi Wisma Pamukti ${ }^{3}$ \\ ${ }^{1,3}$ Teknik Informatika, Universitas Bina Sarana Informatika \\ Indonesia \\ ${ }^{2}$ Sistem Informasi, STMIK Nusa Mandiri \\ Indonesia
}

E-mail:1sunanto.sun@bsi.ac.id, ${ }^{2}$ ina.maryani@nusamandiri.ac.id,3gresiwis1204@bsi.ac.id

Abstract - Cars today have become a primary need for some people, based on the level of usage continues to increase in the community. Furthermore, with these conditions in line with the needs of many people to be able to have the skills to drive a car, many service providers later emerged as car driving courses (driving courses). LPK Citra Indotech Jaya Purwokerto is one of the businesses engaged in car wheel thin services that has been established since 2008 but still uses a manual system, the course registration process can only be done in person or in person. Based on these problems, we need an information system that can provide fast information services to customers, namely a website-based car steering course information system, so to get the information needed, customers do not have to come directly to the location. Participants can register for the course by filling in the registration form and clicking on the register button. When participants arrive at LPK Citra Indotech Jaya only need to show proof of registration to LPK Citra Indotech Jaya. The method used in software development uses a water fall model such as communication, planning, modeling, construction, and deployment. With this web-based car course information system can facilitate participants in registering, expand the LPK marketing area, that is, unlimited promotion and make it easier for the LPK to manage the car steering course system.

\section{Keywords: Information System, Car Steering Course, Course Registration, website.}

\begin{abstract}
Abstrak - Mobil saat ini telah menjadi kebutuhan primer untuk sebagian orang, berdasarkan tingkat penggunaannya terus mengalami peningkatan di masyarakat. Selanjutnya dengan kondisi tersebut sejalan dengan kebutuhan banyak orang untuk dapat memiliki keterampilan mengendarai mobil yang kemudian banyak muncul penyedia jasa layanan kursus setir mobil (driving course). LPK Citra Indotech Jaya Purwokerto adalah salah satu usaha yang bergerak di bidang jasa layanan kurus setir mobil yang sudah berdiri sejak tahun 2008 namun masih menggunakan sistem manual, proses pendaftaran kursus hanya dapat dilakukan secara langsung atau tatap muka. Berdasarkan dari permasalahan tersebut, maka dibutuhkan sebuah sistem informasi yang dapat memberikan layanan informasi cepat kepada pelanggan yaitu sistem informasi kursus setir mobil berbasis website, sehingga untuk mendapatkan informasi yang dibutuhkan, pelanggan tidak harus datang langsung ke lokasi. Peserta dapat melakukan pendaftaran kursus dengan mengisi form pendaftaran dan mengklik tombol daftar. Ketika peserta sampai di LPK Citra Indotech Jaya hanya perlu memperlihatkan tanda bukti pendaftaran kepada pihak LPK Citra Indotech Jaya. Metode yang digunakan pada pengembangan perangkat lunak ini menggunakan model water fall seperti communication, planning, modeling, construction, dan deployment. Dengan adanya sistem informasi kursus
\end{abstract}


setir mobil berbasis web ini dapat mempermudah peserta dalam melakukan pendaftaran, memperluas wilayah pemasaran LPK yaitu adanya promosi tanpa batas dan mempermudah pihak LPK dalam mengelola sistem kursus setir mobil.

Kata Kunci: Sistem Informasi, Kursus Setir Mobil, Pendafataran kursus, website.

\section{A. PENDAHULUAN}

Kemajuan teknologi informasi saat ini turut mengiringi perkembangan dan kemajuan dunia bisnis yang semakin pesat. Persaingan pasar antara perusahaan satu dengan perusahaan lainnya semakin kompetitif. Strategi pemasaran yang dilakukan oleh perusahaan semakin beragam salah satunya dengan memanfaatkan adanya teknologi informasi seperti komputer.

Kecanggihan komputer yang semakin berkembang pesat sangat memudahkan manusia dalam menjalankan kehidupan. Penggunaan komputer yang semakin banyak, membuat para pelaku bisnis memanfaatkan hal tersebut untuk lebih mengembangkan kegiatan bisnisnya. Adanya teknologi internet pada komputer yang semakin canggih akan sangat membantu manusia dalam mengolah suatu informasi.

Internet sangat mempengaruhi perkembangan ekonomi dan bisnis, berbagai transaksi yang sebelumnya hanya dapat dilakukan secara langsung kini dapat dengan mudah dilakukan dari kejauhan hanya dengan menggunakan internet. Transaksi melalui internet dikenal dengan sebutan e-commerce. Dalam penerapan e-commerce media informasi yang digunakan adalah dalam bentuk website.

Website tidak hanya menyediakan informasi namun juga mampu mengolah informasi.

\subsection{Metode Penelitian}

\subsubsection{Metode Pengembangan Perangkat Lunak}

Metode yang digunakan pada pengembangan perangkat lunak ini menggunakan model water fall (Pressman, 2010:39), sebagai berikut:

1. Communication

Langkah ini merupakan analisis terhadap kebutuhan software, dan tahap untuk mengadakan pengumpulan data dengan melakukan pertemuan dengan Bapak Imam selaku pemilik dari LPK Citra Indotech Jaya Purwokerto, maupun mengumpulkan data-data tambahan baik yang ada di jurnal, artikel, dan internet. Dari hasil communication penulis mendapatkan data informasi tentang LPK Citra Indotech Jaya Purwokerto.

2. Planning

Proses planning merupakan lanjutkan dari proses communication (analysis requirment). Tahapan ini akan menghasilkan dokumen user requirment atau bisa dikatakan sebagai data yang berhubungan dengan keinginan user dalam pembuatan software, seperti halaman pendaftaran, halaman transaksi dan data lainnya yang akan digunakan dalam pembuatan website sistem informasi LPK Citra Indotech Jaya Purwokerto.

3. Modeling

Proses modeling ini akan menerjemahkan syarat kebutuhan ke sebuah perancangan software yang dapat diperkirakan sebelum dibuat coding. Proses ini berfokus pada rancangan struktur data seperti data paket, data peserta, data karyawan, data jadwal pelatihan, arsitektur software representasi interfaceseperti 
letak menu, header, konten/isi, sidebar, navbar,footer dan lain-lain. Tahapan ini akan menghasilkan dokumen yang disebut software requirment.

4. Construction

Construction merupakan proses membuat kode. Coding atau pengkodean merupakan penerjemah desain dalam bahasa yang biasa dikenali oleh komputer. Disini penulis menggunakan bahasa pemrograman html dalam pembuatan website. Setelah pengkodean selesai maka akan dilakukan testing terhadap sistem yang telah dibuat tadi. Tujuan testing adalah menemukan kesalahankesalahan terhadap sistem tersebut untuk kemudian bisa diperbaiki.

5. Deployment

Setelah melakukan analisis, desain dan pengkodean maka website yang sudah jadi akan digunakan oleh user untuk pendaftaran, transaksi dan sebagainya.

\subsubsection{Teknik Pengumpulan Data}

Teknik yang digunakan dalam melakukan pengumpulan data untuk pembuatan system ini adalah:

1. Wawancara

Pada metode ini diajukan beberapa pertanyaan secara lisan dengan pemilik LPK Citra Indotech Jaya yaitu Bapak Imam tentang hal-hal yang berkaitan dengan sistem informasi, misalnya data karyawan, data paket, dan berbagai macam data yang dibutuhkan dalam proses pendaftaran dan transaksi kursus setir mobil kemudian visi misi, sejarah dan profil perusahaan.

2. Pengamatan

Pada metode ini dilakukan analisa pengamatan tentang tata cara pendaftaran dan transaksi yang masih dilakukan secara manual pada LPK Citra Indotech Jaya.
3. Studi Pustaka

Selain metode observasi dan wawancara teknik pengumpulan data juga dilakukan dengan menggunakan metode pustaka yaitu dengan mengumpulkan data dan informasi dengan membaca buku-buku, melakukan browsing di internet, dan mencari referensi-referensi yang berkaitan erat dengan penulisan penelitian ini.

\section{B. Landasan Teori}

\subsection{Konsep Dasar Web}

Dalam pembuatan website ini penulis akan memberikan penjelasan tentang konsep dasar dalam perancangan website. Tujuan pembuatan konsep dasar ini agar website yang dibuat sesuai dengan apa yang diharapkan. Konsep dasar ini menjelaskan tentang semua hal yang berhubungan dengan pembuatan website.

\subsubsection{Sistem Informasi}

Menurut Paryati dan Yosef (2008:29) menyimpulkan bahwa:

Sistem informasi merupakan system yang berada pada organisasi yang didalamnya terdapat sekelompok orang-orang, teknologi, media, fasilitas, prosedur-prosedur dan pengendalian yang digunakan untuk tujuan mendapatkan jalur komunikasi, memproses transaksi secara rutin, memberi sinyal kepada manajemen mengenai kejadian-kejadian internal dan eksternal dan menyediakan informasi yang dapat digunakan sebagai pengambilan keputusan.

\subsubsection{Internet}

Secara sederhana dapat dikatakan internet adalah sebuah "jaringan komputer dunia". Menurut Yeni dan Devie (2011:2) "Internet, yaitu kepanjangan dari interconnection networking atau juga yang telah menjadi international networking merupakan suatu jaringan yang menghubungkan komputer diseluruh 
dunia tanpa dibatasi oleh jumlah unit menjadi satu jaringan yang bisa saling mengakses."

\section{Website}

Menurut Puspitosari (2010:1)

"Website adalah halaman informasi yang disediakan melalui jalur internet sehingga bisa diakses di seluruh dunia, selama terkoneksi dengan jaringan internet."Website merupakan komponen atau kumpulan komponen yang terdiri dari teks, gambar, suara, dan animasi sehingga lebih merupakan media informasi yang menarik untuk dikunjungi.

\subsubsection{Bahasa Pemrograman}

1. HTML

Hyper Text Markup Language (HTML) dalam ilmu komputer merupakan bahasa pemrograman teks untuk dokumen-dokumen pada jaringan komputer yang dikenal sebagai World Wide Web atau sering disebut sebagai Web saja.

\section{PHP}

Menurut Abdul Kadir (2008:2) "PHP merupakan singkatan dari $P H P$ Hypertext Preprocessor. Ia merupakan bahasa berbentuk skrip yang ditempatkan dalam server dan diproses di server." Hasilnya yang dikirimkan ke klien, tempat pemakai menggunakan browser.

3. CSS

Menurut Yenie dan Devie, dkk (2011:47) Style sheet merupakan feature yang sangat penting dalam membuat web, akan tetapi penggunaan style sheets merupakan kelebihan tersendiri. Suatu style sheet merupakan tempat di mana mengontrol dan memanage style-style yang ada. Style sheet mendeskripsikan bagaimana tampilan documen HTML di layar. Secara teoritis kita bisa menggunakan style sheet technology dengan HTML. Akan tetapi pada praktiknya hanya
Cascading Style Sheet (CSS) technology yang support pada hampir semua web browser.

\section{JavaSript}

Menurut Yeni dan Devie (2011:65), "JavaScript adalah bahasa yang berbentuk kumpulan skrip berjalan pada suatu dokumen HTML." Bahasa ini adalah bahasa pemrograman untuk memberikan kemampuan tambahan terhadap bahasa HTML dengan mengizinkan pengeksekusian perintahperintah di sisi user artinya di sisi browser bukan di sisi server web.

\subsubsection{Basis Data}

Menurut Rosa dan Shalahudin (2013:43), "SistemBasis data adalah sistem terkomputerisasi yang tujuan utamanya adalah memelihara data yang sudah diolah atau informasi dan membuat informasi tersedia saat dibutuhkan." Pada intinya basis data adalah media untuk menyimpan data agar diakses dengan mudah dan cepat.

1. $M y S Q L$

Menurut Kristanto(2010:219), "MySQL (My Structure Query Language) merupakan sebuah program pembuat database yang bersifat open source, artinya semua orang dapat menggunakannya dan dapat dijalankan pada semua platform baik Windows maupun Linux."MySQL juga merupakan sebuah perangkat lunak sistem manajemen basis data $S Q L$ yang bersifat jaringan sehingga dapat digunakan untuk aplikasi Multi User (banyak pengguna).

2. Php My Admin

Menurut Nugroho (2008:88) mendefinisikan bahwa "phpMyAdmin adalah suatu apalikasi open source yang berbasis web, aplikasi ini dibuat menggunakan program PHP, fungsi dari aplikasi ini adalah untuk mengakses database MySQL." 
Dengan adanya aplikasi ini akan sangat mempermudah dan mempersingkat suatu pekerjaan dalam mengelola database $M y S Q L$.

\subsubsection{Aplikasi Perangkat Lunak}

1. Sublime Text

Menurut Supono

"Sublime Text merupakan perangkat lunak text editor yang digunakan untuk membuat atau mengedit suatu aplikasi”. Sublime Text mempunyai fitur plugin tambahan yang memudahkan programmer.

2. XAMPP

Menurut Wicaksono (2008:7) mendefinisikan bahwa:"XAMPP adalah software yang berfungsi untuk menjalankan website berbasis PHP dan menggunakan pengolahan data MySQL di komputer lokal". XAMPP berperan sebagai server web pada sebuah komputer. XAMPP dikembangkan oleh Apache Friends yang merupakan sebuah website non-komersial yang bertujuan untuk mempromosikan web server Apache.

3. Bootstrap

Bootstrap merupakan proyek open source dan tentunya pemakaiannya bersifat gratis. Saat ini, Bootstrap menjadi aplikasi paling populer di situs layanan hosting software open source GitHub.com. Jutaan website telah menggunakan Bootstrap sebagai framework desainnya. Menurut Zaenal dan SmitDev Community (2015:1), "Bootstrap adalah paket aplikasi siap pakai untuk membuat frontend sebuah website".

4. Codeigniter

Menurut Sirenden dan Bernadus Herdi (2012:3) "CodeIgniter(CI) adalah salah satu framework php yang tangguh dengan ukuran kecil dan cukup mudah
dikuasai."Frameworkatau dalam bahasa indonesia dapat diartikan sebagai "kerangka kerja" merupakan sebuah tool yang bekerja pada suatu konsep tertentu dan terdiri dari berbagai fungsi yang dapat dengan mudah dijabarkan atau dialih-gunakan untuk membuat fungsi-fungsi lain yang lebih kompleks.

5. JQuery

JQuery digunakan agar tampilan website lebih bagus dan mempermudah dalam proses pengkodingan. Menurut Anastasia (2013:58) JQuery merupakan "library / framework dari JavaScript yang dapat mempermudah pengolahan DOM pada halaman website. JQuery menekankan interaksi antara JavaScript dan HTML".

6. Ckeditor

MenurutYuhefizar $(2010: 234)$ mengemukakanbahwa,

"CKeditorjuga editor CMS Joomlaberbasis WYSWYG yang populer. Editor inimengklaimdirinyasebagai editor yang tidaksajafleksibeldancepat, tapiinovatif, smartdanuser friendly".

\subsubsection{Model Pengembangan Perangkat Lunak}

Metode System Development Life Cycle atau SDLC digunakan oleh analis sistem untuk mengembangkan sistem, mulai dari penentuan kebutuhan, perancangan, validasi, sampai pelatihan dan penyerahan kepada konsumen.Metode yang digunakan pada pengembangan perangkat lunak ini menggunakan metode waterfall.

\subsubsection{Struktur Navigasi}

Bentuk dasar struktur navigasi menurut Sutopo (2007:5) sebagai berikut: 
1. Linear navigation model

Linear navigation model digunakan oleh sebagian besar website. Informasi diberikan secara sekuensial dimulai dari satu halaman. Beberapa desainer menggunakan satu halaman untuk masuk atau keluar dari website.

2. Hierarchical model

Hierarchical model diadaptasikan dari top-down design. Konsep navigasi ini dimulai dari satu node yang menjadi homepage. Dari homepage dapat dibuat beberapa cabang ke halaman-halaman utama. Apabila diperlukan, dari tiap halaman utama dapat dikembangkan menjadi beberapa cabang lagi. Hal ini seperti struktur organisasi dalam perusahaan.

3. Spoke and hub model

Spoke and hub model hanya menggunakan satu node untuk berhubungan dengan node lain. Pada model ini hanya terdapat dua macam link, yaitu dari homepage ke halaman tertentu, dan dari halaman tersebut kembali ke homepage.

4. Full web model

Full web model memberikan kemampuan hyperlink yang banyak. Full web model banyak digunakan karena user dapat mengakses semua topik dengan subtopik dengan cepat. Namun kelemahan dari model ini, yaitu dapat berakibat user kehilangan cara untuk kembali ke topik sebelumnya.

\subsubsection{Entity Relationship Diagram}

$E R D$ digunakan untuk permodelan basis data relasionship. Sehingga jika penyimpanan basis data menggunakan OODBMS maka perancangan basis data tidak perlu menggunakan ERD.ERD biasanya memiliki binary (satu relasi menggabungkan dua buah entitas).

\subsubsection{Logical Record Structure}

Menurut Andriansyah (2016:53) "LRS merupakan transformasi dari penggambaran ERD dalam bentuk yang lebih jelas dan mudah untuk dipahami".

\subsubsection{Pengujian $W e b$}

Menurut Rosa dan Shalahuddin (2013:275) "Black-box testing (pengujian kotak hitam) yaitu menguji perangkat lunak dari segi spesifikasi fungsional tanpa menguji desain dan kode program.

Kasus uji yang dibuat untuk melakukan pengujian kotak hitam harus dibuat dengan kasus benar dan kasus salah, misalkan untuk kasus proses login maka kasus yang dibuat menurut Rosa dan Shalahuddin (2013:276) sebagai berikut:

1. Jika user memasukkan nama pemakai (username) dan kata sandi (password) yang benar.

2. Jika user memasukkan nama pemakai (username) dan kata sandi (password) yang salah, misalnya nama pemakai benar tapi kata sandi salah, atau sebaliknya, atau keduanya salah.

Kelebihan Black Box:

1. Bisa memilih subset test secara efektif dan efisien.

2. Dapat menemukan cacat.

3. Memaksimalkan testinginvestmen.

\section{PEMBAHASAN}

\subsection{Analisis Kebutuhan}

\subsubsection{Analisis Kebutuhan Pengguna}

Penggunaan internet saat ini sudah menjadi hal biasa di kalangan masyarakat. Pemanfaatan teknologi di dunia bisnis sudah mulai dilakukan untuk menunjang proses pengolahan data dan informasi yang mudah dan tertarget. Sistem informasi kursus setir mobil berbasis web merupakan proses penyampaian informasi tanpa perlu bertatap muka secara langsung dan dapat meluas tanpa batas dalam penyampaiannya. Masyarakat cukup memanfaatkan internet untuk dapat memperoleh informasi tersebut. 
Berikut kebutuhan pengguna dari sistem informasi kursus setir mobil berbasis website.

1. Halaman Utama

a. Pengunjung dapat melihat informasi profil.

b. Pengunjung dapat melihat informasi paket yang tersedia.

c. Pengunjung dapat melakukan pendaftaran kursus setir mobil.

d. Pengunjung dapat melihat galeri.

e. Pengunjung dapat melihat dan mengisi testimoni.

f. Pengunjung dapat melakukan kontak melalui website.

2. Halaman Admin
a. Admin dapat mengolah data paket, peserta, instruktur, dan jadwal.
b. Admin dapat mengolah konten artikel dan galeri.
c. Admin dapat mengolah data pendaftaran masuk
d. Admin dapat mengolah profil perusahaan.
e. Admin dapat mengolah data admin.

\subsubsection{Analisa Kebutuhan Sistem}

Website sistem informasi kursus setir mobil pada LPK Citra Indotech Jayamemiliki kebutuhan sistem sebagai berikut:

1. Data

a. Data LPK

Data LPK berkaitan dengan informasi LPK seperti profil, kontak, foto galeri, dan testimoni.

b. Data Pendaftaran

Data pendaftaran merupakan datadata yang dibutuhkan dalam proses pengolahan sistem informasi kursus setir mobil bagi peserta seperti data paket, data instruktur, data jadwal dan data pribadi.

2. Hak Akses

Sistem informasi kursus setir mobil dibuat agar dapat diakses oleh beberapa tingkatan pengguna. a. Pengunjung

Pengunjung website hanya dapat mengakses atau melihat informasi secara umum yang terdapat dihalaman web, seperti profil, paket kursus, pendaftaran kursus, galeri, testimoni dan hubungi kami.

b. Admin

Admin bertanggungjawab untuk mengatur aktifitas website. Admin memiliki hak akses untuk menambahkan, mengubah dan menghapus semua data website.

3. Keamanan

Sistem Informasi Kursus Setir Mobil memerlukan sistem keamanan agar terhindar dari pihak-pihak yang tidak bertanggungjawab, sistem keamanan yang dimaksud adalah, Password admin di enkripsi agar tidak diketahui oleh pihak lain.

4. Kebutuhan Perangkat Keras (Hardware)

Kebutuhan perangkat keras (hardware) yang dibutuhkan dalam pembuatan website Sistem Informasi Kursus Setir Mobil pada LPK Citra Indotech Jaya antara lain:

a. Monitor: 1366 x 78 (32 bit) $(60 \mathrm{~Hz})$

b. Prosessor : Intel(R) Core(TM) i32348M CPU@2.30GHz (4 CPUs)

c. Ram : 2048MB

d. Memori Layar Resolusi 1366 x 768 (32 bit) $(60 \mathrm{~Hz})$

e. Laptop atau Netbook

f. Mouse atau Keyboard

5. Kebutuhan Perangkat Lunak (Software)

a. Windows 7

b. Sublime Text

c. Bootstrap

d. Codeigniter

e. JQuery

f. Ckeditor

g. XAMPP Versi 1.7.3

3.3. Perancangan Perangkat Lunak 


\subsubsection{Perancangan Antar Muka}

Berikut ini adalah rancangan antar muka pada website Sistem Informasi Kursus Setir Mobil:

1. Halaman Pengunjung

Halaman ini dikhususkan untuk pengunjung yang ingin melihat informasi tentang LPK Citra Indotech Jaya. Rancangan antarmuka halaman pengunjung sebagaiberikut:

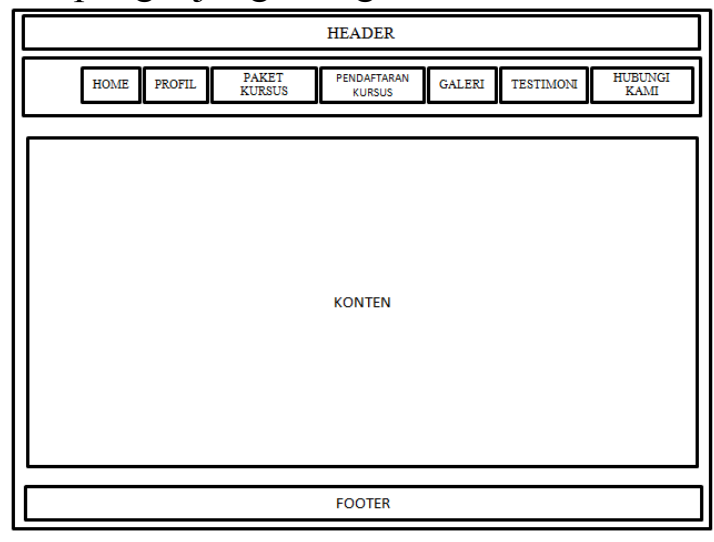

Gambar III.2.RancanganAntarmuka Halaman Pengunjung

Rancangan antarmuka halaman pengunjung terdiri dari lima bagian yaitu:

\section{a. Header}

Berisi logo dan nama LPK Citra Indotech Jaya. Gambar header ini dijadikan banner sebagai identitas website.

b. Konten

Bagian ini merupakan kolom utama untuk menampilkan gambar.

c. Footer

Berisi tahun pembuatan, nama website dan pembuat website. Isi footer dijadikan identitas pembuatan website.

d. Menu, berupa :

1) Home

Halaman menu Home : Berisi ucapan "Selamat datang di Website Resmi LPK Citra Indotech Jaya".Rancangan antarmuka halaman menu home sebagai berikut:

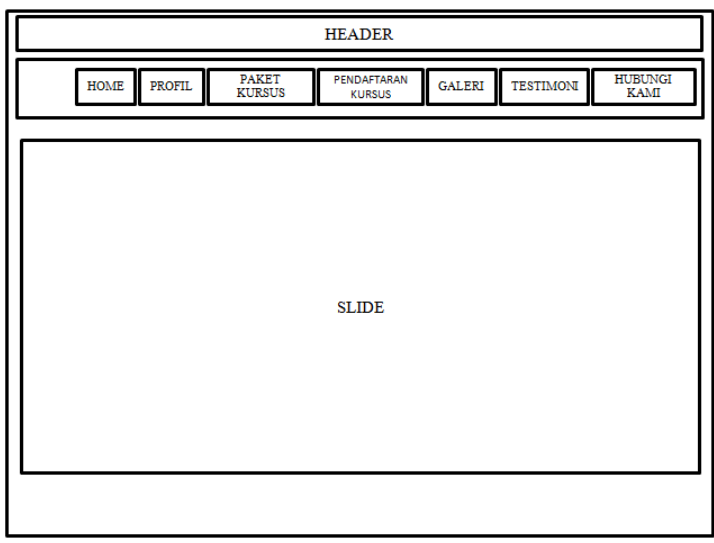

Gambar III.3. Rancangan

Antarmuka Halaman Menu Home

2) Profil

Berisi tentang profil singkat seperti visi dan misi dari LPK Citra Indotech Jaya Purwokerto.

3) Paket Kursus

Berisi tentang berbagai macam paket kursus dan penjelasannya, Rancangan antarmuka

4) Pendaftaran Kursus

Halaman ini dikhususkan untuk user yang akan melakukan pendaftaran kursus.

5) Galeri

Berisi foto Tentang fasilitas dan kegiatan yang ada di LPK Citra Indotech Jaya Purwokerto terdapat pula keterangan nama gambar.

6) Testimoni

Halaman ini menampilkan berbagai pesan yang ditulis oleh pengunjung yang mengunjungi website dan menulis pesan di halaman hubungi kami.

7) Hubungi Kami

Halaman ini dapat digunakan oleh pengunjung untuk yang dapat dihubungi oleh pengunjung.

2. Halaman Admin

Halaman ini dikhususkan bagi admin LPK Citra Indotech Jaya Purwokerto untuk melihat data yang berhubungan dengan sistem informasi kursus setir mobil yang ada. Untuk 
mengakses halaman ini, diperlukan otentifikasi login admin.

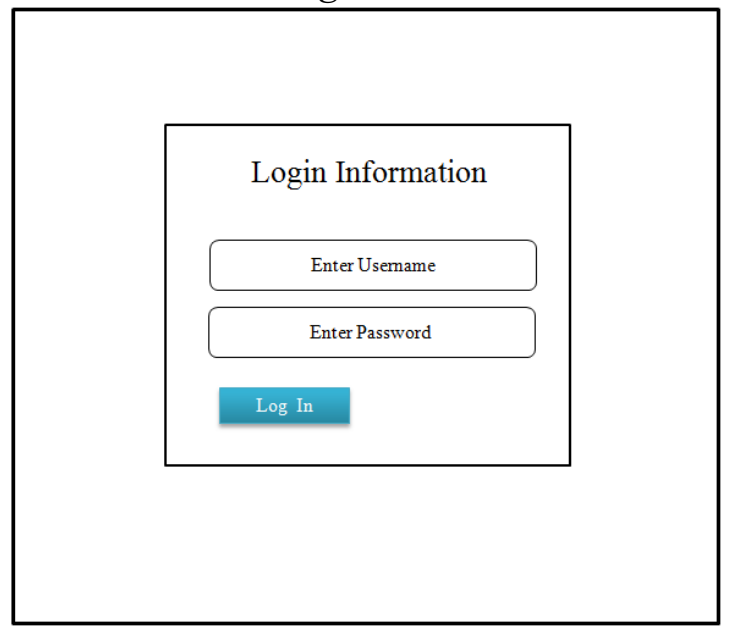

Gambar III.10. Rancangan Antarmuka

\section{Halaman Login Admin}

Setelah berhasil login, admin akan dialihkan ke halaman utama index admin. Berikut rancangan antarmuka halaman utama ruang admin:

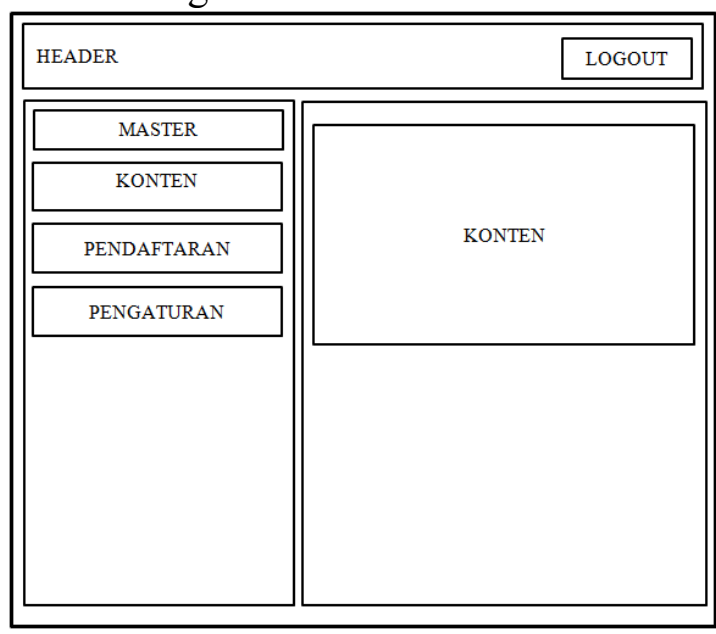

Gambar III.11. Rancangan Antarmuka Halaman Admin

a. Header

Berisi nama dan keterangan ruang admin.

b. Logout

Berfungsi untuk keluar dari ruang admin dan kembali lagi ke tampilan awal menu login admin.

c. Konten

Berisi hasil dari kiriman link yang ada di halaman admin . d. Menu

1) Master

a) Jenis Paket

Berisi form untuk mengolah data jenis paket.Rancangan antarmuka halaman menu admin jenis paket sebagai berikut:

\begin{tabular}{|c|c|c|c|c|}
\hline \multicolumn{4}{|l|}{ HEADER } & LOGOUT \\
\hline MASTER & \multicolumn{4}{|c|}{ Beranda/ Master / Jenis paket } \\
\hline JENIS PAKET & & & & \multirow[b]{2}{*}{ + Tambah } \\
\hline PESERTA & & & & \\
\hline INSTRUKTUR & \multicolumn{2}{|c|}{$\nabla$} & \multicolumn{2}{|c|}{ pencarian } \\
\hline JADWAL & \multirow{2}{*}{\begin{tabular}{|l|}
$\begin{array}{l}\text { Kode } \\
\text { paket }\end{array}$ \\
\end{tabular}} & \multirow[b]{2}{*}{$\begin{array}{l}\text { Nama } \\
\text { paket }\end{array}$} & \multirow[b]{2}{*}{ Harga } & \multirow[b]{2}{*}{\begin{tabular}{|c|c} 
Deskr \\
ipsi \\
\end{tabular}} \\
\hline KONTEN & & & & \\
\hline PENDAFTARAN & $x x x x x$ & $x \mathrm{x} x \mathrm{xx}$ & $x x x x x$ & $x x x x x$ \\
\hline \multirow[t]{2}{*}{ PENGATURAN } & $x x x x x$ & $x x x x x$ & $x x x x x$ & $x x x x x$ \\
\hline & & $x x x x y x$ & 1 & $x x x x x$ \\
\hline
\end{tabular}

Gambar III.12. Rancangan Antarmuka Halaman Menu Admin Jenis Paket

b) Peserta

Berisi form untuk mengolah data peserta.

c) Instruktur Berisi form untuk mengolah data instruktur.

d) Jadwal

Berisi form untuk mengolah data jadwal.

2) Konten

a) Galeri

Berisi form untuk mengolah data galeri.

\begin{tabular}{|c|c|c|c|}
\hline HEADER & & \multicolumn{2}{|c|}{ LOGOUT } \\
\hline MASTER & \multicolumn{3}{|l|}{ Beranda/ Master / Galeri } \\
\hline KONTEN & & \multicolumn{2}{|c|}{ +Tambah } \\
\hline Galeri & & & \\
\hline Buku Tamu & $\mathbf{\nabla}$ & \multicolumn{2}{|c|}{ pencarian } \\
\hline PENDAFTARAN & Judul & \multicolumn{2}{|c|}{ Galeri } \\
\hline \multirow[t]{2}{*}{ PENGATURAN } & & & \\
\hline & $\mathrm{xxxxxxx}$ & 1 & $\begin{array}{c}\mathrm{xxxx} \\
\mathrm{x}\end{array}$ \\
\hline
\end{tabular}


Gambar III.16. Rancangan Antarmuka Halaman Menu Admin Galeri
Gambar III.22. TampilanEntity

Relationship Diagram (ERD) b) Buku Tamu

Berisi form untuk mengolah buku tamu berupa pesan pengunjung.

3) Pendaftaran

a) Data Masuk

Berisi data pendaftaran yang telah masuk.

\begin{tabular}{|c|c|c|c|c|c|c|}
\hline \multicolumn{5}{|l|}{ HEADER } & \multicolumn{2}{|c|}{ LOGOUT } \\
\hline MASTER & \multicolumn{6}{|c|}{ Beranda / Pendaftaran / Data Masuk } \\
\hline KONTEN & \multicolumn{6}{|c|}{ +Tambah } \\
\hline PENDAFTARAN & \multirow{2}{*}{\multicolumn{3}{|c|}{$\nabla$}} & \multirow{2}{*}{\multicolumn{3}{|c|}{ pencarian }} \\
\hline Data Masuk & & & & & & \\
\hline \multirow[t]{4}{*}{ PENGATURAN } & $\begin{array}{lll}\text { Id } \\
\text { Pendaturan }\end{array}$ & tangal & nama & Ip & Alamat & 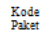 \\
\hline & $x \times x x$ & $x \mathrm{xxx}$ & $x x x x$ & $x_{x}^{x \rightarrow x}$ & $x x x x$ & $x x x x$ \\
\hline & $\mathrm{xxxx}$ & $x \mathrm{xxx}$ & $x \mathrm{xxx}$ & $x_{x}^{x x x}$ & $\pi x x x$ & $x x x x$ \\
\hline & \multicolumn{4}{|c|}{$\operatorname{xxxxxxx}$} & 1 & $x \mathrm{xxx}$ \\
\hline
\end{tabular}

Gambar III.18. Rancangan Antarmuka Halaman Menu Admin Data Masuk

4) Pengaturan

a) Profil

Berisi form untuk mengatur dan mengolah data profil.

b) Header

Berisi form untuk mengatur data tampilan header.

c) Password

Berisi form ubah password admin.

\subsubsection{Rancangan Basis Data}

1. Entity Relationship Diagram

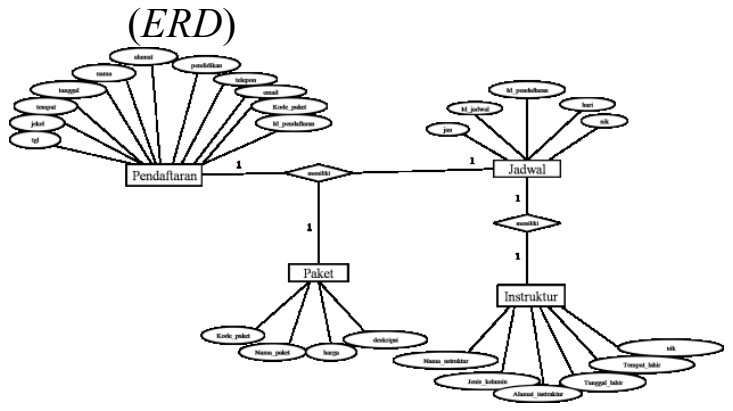

2. Logical Record Structure (LRS)

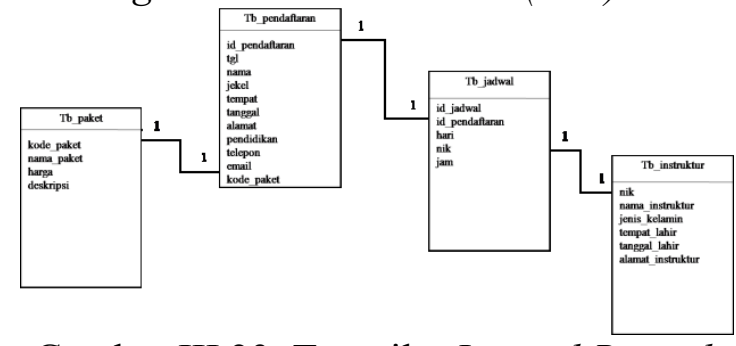

Gambar III.23. TampilanLogical Record Structure (LRS)

3. Spesifikasi File

Adapun rincian database pada perancangan website ini sebagai berikut:

Nama Database $\quad:$ db_kursus

Program Aplikasi : MySQL

Jumlah Tabel $\quad: 8$ tabel

a. tb_admin

b. tb_galery

c. tb_instruktur

d. tb_jadwal

e. tb_paket

f. tb_pendaftaran

g. tb_pengaturan

h. tb_pesanpengunjung

\subsubsection{Rancangan Struktur Navigasi}

Untuk mempermudah dalam perancnagan web ini, maka rancangan yang harus dibuat harus digambarkan terlebih dahulu. Hal ini dimaksudkan agar memperjelas dalam perancangan tampilan. 
1. Struktur Naigasi User

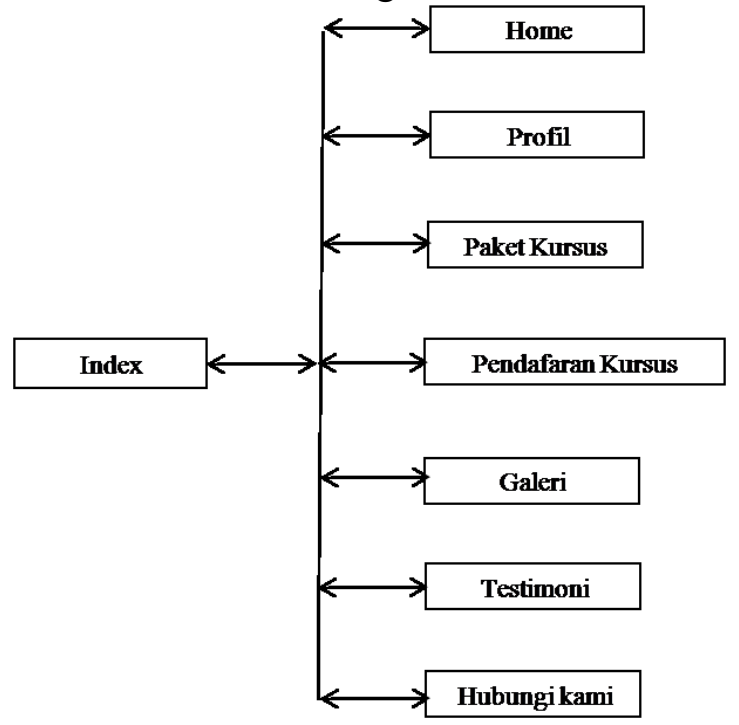

Gambar III.24.Rancangan Struktur Navigasi User

2. Rancangan Struktur Navigasi Admin

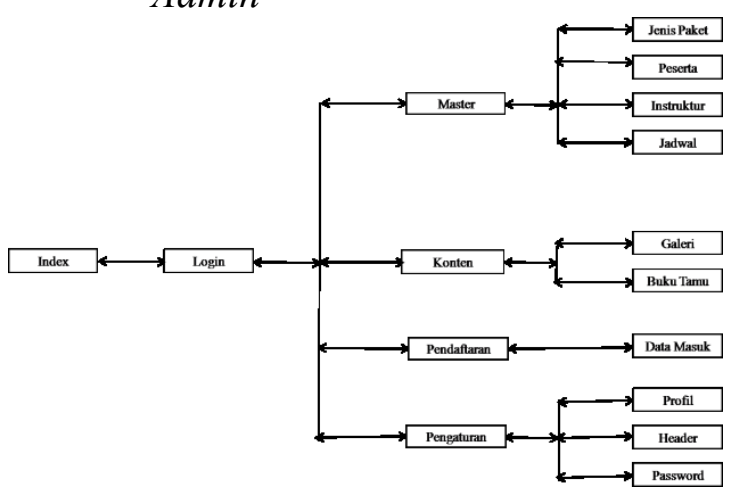

Gambar III.25.Rancangan Struktur Navigasi Admin

\subsection{Implementasi dan Pengujian Unit}

\subsubsection{Implementasi}

1. Implementasi Antar Muka Halaman Pendaftaran Kursus

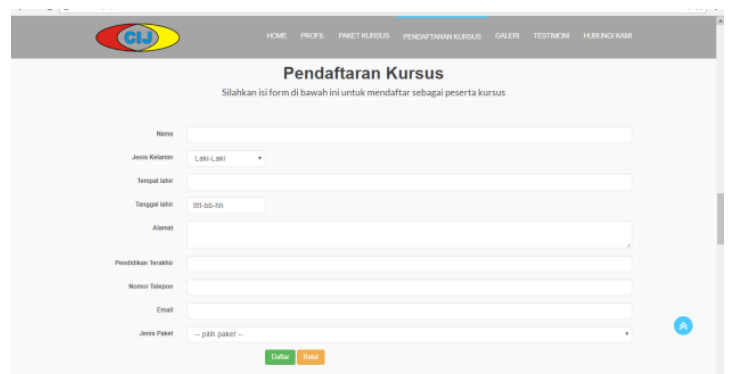

Gambar III. 29.Implementasi Antar Muka Halaman Pendaftaran Kursus
2. Implementasi Antar Muka Halaman Hubungi Kami

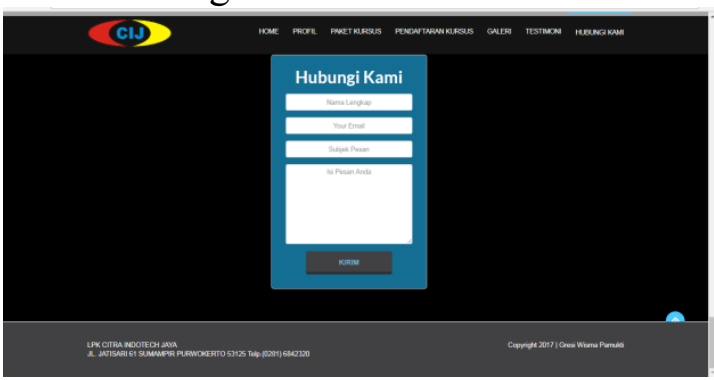

Gambar III. 32. Implementasi Antar Muka Halaman Hubungi Kami

3. Implementasi Antar Muka Halaman Admin

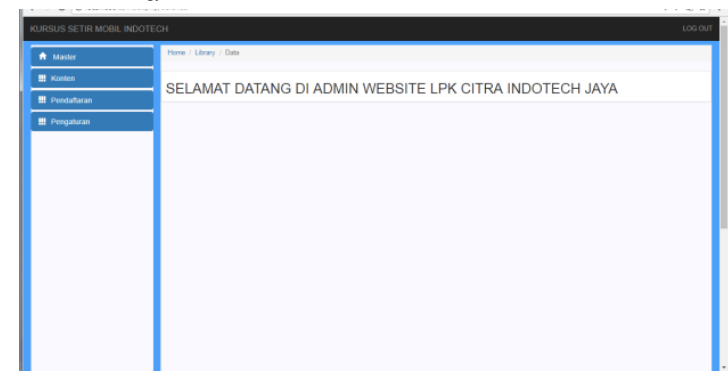

Gambar III.34.Implementasi Antar Muka Halaman Admin

\subsubsection{Pengujian Unit}

\section{Black Box Testing Admin}

Tabel III.9.

Tabel Pengujian Black Box

Testing Halaman Login Admin

\begin{tabular}{|c|c|c|c|c|c|}
\hline No. & $\begin{array}{l}\text { Skena } \\
\text { rio } \\
\text { Pengu } \\
\text { jian }\end{array}$ & $\begin{array}{l}\text { Test } \\
\text { Case }\end{array}$ & $\begin{array}{l}\text { Hasil } \\
\text { yang } \\
\text { diharap } \\
\text { kan }\end{array}$ & $\begin{array}{l}\text { Hasil } \\
\text { Peng } \\
\text { ujian }\end{array}$ & $\begin{array}{l}\text { Kesi } \\
\text { mpul } \\
\text { an }\end{array}$ \\
\hline 1. & $\begin{array}{l}\text { Usern } \\
\text { ame, } P \\
\text { asswo } \\
r d, \\
\text { kemud } \\
\text { ian } \\
\text { klik } \\
\text { tombo } \\
1 \text { login }\end{array}$ & $\begin{array}{l}\text { Usern } \\
\text { ame:( } \\
\text { koson } \\
\mathrm{g}) \\
\text { Passw } \\
\text { ord:(k } \\
\text { osong) }\end{array}$ & $\begin{array}{l}\text { Sistem } \\
\text { akan } \\
\text { menola } \\
\mathrm{k} \text { akses } \\
\text { login } \\
\text { dan } \\
\text { menam } \\
\text { pilkan } \\
\text { halama } \\
\mathrm{n} \text { awal } \\
\text { login }\end{array}$ & $\begin{array}{l}\text { Sesua } \\
\mathrm{i} \\
\text { harap } \\
\text { an }\end{array}$ & Valid \\
\hline 2. & $\begin{array}{l}\text { Meng } \\
\text { etikka } \\
\text { nusern } \\
\text { ame, } \\
\text { dan } \\
\text { Passw }\end{array}$ & $\begin{array}{l}\text { Usern } \\
\text { ame: } \\
\text { (terisi } \\
\text { salah) } \\
\text { Passw } \\
\text { ord:(k }\end{array}$ & $\begin{array}{l}\text { Sistem } \\
\text { akan } \\
\text { menola } \\
\mathrm{k} \text { akses } \\
\text { login } \\
\text { dan }\end{array}$ & $\begin{array}{l}\text { Sesua } \\
\mathrm{i} \\
\text { harap } \\
\text { an }\end{array}$ & Valid \\
\hline
\end{tabular}




\begin{tabular}{|c|c|c|c|c|c|}
\hline & $\begin{array}{l}\text { ordtid } \\
\text { ak } \\
\text { diisi } \\
\text { atau } \\
\text { koson } \\
\text { g } \\
\text { kemud } \\
\text { ian } \\
\text { klik } \\
\text { tombo } \\
\text { l login }\end{array}$ & osong) & $\begin{array}{l}\text { menam } \\
\text { pilkan } \\
\text { halama } \\
\mathrm{n} \text { awal } \\
\text { login }\end{array}$ & & \\
\hline 3. & $\begin{array}{l}\text { Meng } \\
\text { etikka } \\
\mathrm{n} \\
\text { userna } \\
\text { me } \\
\text { dan } \\
\text { Passw } \\
\text { ord, } \\
\text { atau } \\
\text { koson } \\
\text { g } \\
\text { kemud } \\
\text { ian } \\
\text { klik } \\
\text { tombo } \\
\text { l login }\end{array}$ & $\begin{array}{l}\text { Usern } \\
\text { ame: } \\
\text { (terisi } \\
\text { salah) } \\
\text { Passw } \\
\text { ord: } \\
\text { (terisi } \\
\text { salah) }\end{array}$ & $\begin{array}{l}\text { Sistem } \\
\text { akan } \\
\text { menola } \\
\mathrm{k} \text { akses } \\
\text { login } \\
\text { dan } \\
\text { menam } \\
\text { pilkkan } \\
\text { halama } \\
n \text { awal } \\
\text { login }\end{array}$ & $\begin{array}{l}\text { Sesua } \\
\text { i } \\
\text { harap } \\
\text { an }\end{array}$ & Valid \\
\hline 4. & $\begin{array}{l}\text { Meng } \\
\text { etikka } \\
\mathrm{n} \\
\text { nama } \\
\text { userna } \\
\text { me } \\
\text { dan } \\
\text { Passw } \\
\text { ord, } \\
\text { dan } \\
\text { kemud } \\
\text { ian } \\
\text { klik } \\
\text { tombo } \\
\text { l login }\end{array}$ & $\begin{array}{l}\text { Usern } \\
\text { ame: } \\
\text { (terisi } \\
\text { benar) } \\
\text { Passw } \\
\text { ord: } \\
\text { (terisi } \\
\text { salah) }\end{array}$ & $\begin{array}{l}\text { Sistem } \\
\text { akan } \\
\text { menola } \\
\mathrm{k} \text { akses } \\
\text { login } \\
\text { dan } \\
\text { menam } \\
\text { pilkan } \\
\text { halama } \\
\mathrm{n} \text { awal } \\
\text { login }\end{array}$ & $\begin{array}{l}\text { Sesua } \\
\text { i } \\
\text { harap } \\
\text { an }\end{array}$ & Valid \\
\hline 5. & $\begin{array}{l}\text { Meng } \\
\text { etikka } \\
\mathrm{n} \\
\text { nama } \\
\text { userna } \\
\text { me } \\
\text { dan } \\
\text { Passw } \\
\text { ord, } \\
\text { dan } \\
\text { kemud } \\
\text { ian } \\
\text { klik } \\
\text { tombo } \\
\text { l login }\end{array}$ & $\begin{array}{l}\text { Usern } \\
\text { ame: } \\
\text { (terisi } \\
\text { benar) } \\
\text { Passw } \\
\text { ord: } \\
\text { (terisi } \\
\text { benar) }\end{array}$ & $\begin{array}{l}\text { Sistem } \\
\text { akan } \\
\text { meneri } \\
\text { ma } \\
\text { akses } \\
\text { login } \\
\text { dan } \\
\text { menam } \\
\text { pilkan } \\
\text { halama } \\
\text { n } \\
\text { admin" }\end{array}$ & $\begin{array}{l}\text { Sesua } \\
\text { i } \\
\text { harap } \\
\text { an }\end{array}$ & Valid \\
\hline
\end{tabular}

\section{PENUTUP}

\subsection{Kesimpulan}

Berdasarkan hasil analisa dan pembahasan yang telah disusun dari mengenai perancangan sistem informasi kursus setir mobil berbasis web pada LPK Citra Indotech Jaya Purwokerto, maka dapat diambil kesimpulan sebagai berikut: Pemanfaatan media informasi berbasis web dapat membantu LPK Citra Indotech Jaya Purwokerto dalam mempromosikan jasa kursus setir mobil, Media informasi berbasis web dapat mempermudah pengguna internet untuk mengetahui informasi dari LPK Citra Indotech Jaya lebih cepat, tanpa harus datang secara langsung, Pembuatan sistem informasi kursus setir mobil berbasis web merupakan salah satu langkah untuk melakukan efisiensi, dan penghematan waktu, tenaga dan biaya, Dengan adanya menu Galeri di dalam website, mempermudah pengguna internet untuk melihat fasilitas dan kegiatan apa saja yang ada di LPK Citra Indotech Jaya Purwokerto.

\section{DAFTAR PUSTAKA}

[1] Anastasia, Meilan M.2013. Trikmenguasai PHP + JQuery berbasis Linux \& Windows, Yogyakarta: Lokomedia.

[2] A.Rozi, Zaenal dan Smit DevCommunity. 2015. Bootstrap Design Framework. Jakarta: PT.Elex Media Komputindo.

[3] A.S, Rosa dan M. Shalahuddin. 2013. Rekayasa Perangkat Lunak, Terstruktur Dan Berorientasi Objek. Bandung: Informatika Bandung.

[4] Andriansyah, Doni. 2016. Sistem Informasi Pendaftaran Event Dengan PHP Untuk Panduan Skripsi.Cirebon Jawa Barat:C.V ASFA Solution. 
[5] Ariesto, Hadi Sutopo. 2007.Multimedia Interaktif dengan Flash. Yogyakarta: GRAHA ILMU.

[6] Kadir, Abdul.2008. Dasar Pemrograman $W e b$ Dinamis Menggunakan PHP(Revisi). Yogyakarta:CV. ANDI OFFSET.

[7] Kristanto, Andri. 2010. Kupas Tuntas PHP \&Mysql. Klaten: Cable Book.

[8] KustiyahNingsih, Yeni dan Devie Rosa Anamisa. 2011. Pemrograman Basis Data Berbasis Web Menggunakan PHP Dan Mysql. Yogyakarta:GRAHA ILMU.

[9] Nugroho, Bunafit. 2009.Latihan Membuat Aplikasi Web, PHPDan Mysql Dengan Dreamweaver. Yogyakarta: GAVA MEDIA.

[10] Paryati dan Yosef Murya Kusuma Ardhana. 2007. Sistem Informasi. Yogyakarta: Ardana media.

[11] Puspitosari, Heni A.2010. Membangun Website Interaktif Dengan Adobe Creative Suite 5 Tingkat Dasar.Yogyakarta:PT. Skripta Media Creative.

[12] Roger, S. Pressman. 2010. Software Engineering.Diambil dari archive.org.( 21 April 2017)

[13] Simarmata, Janner Dan Imam Paryudi. 2010. Basis Data. Yogyakarta: C.V ANDI OFFSET.

[14] Sirenden dan Bernadus Herdi. 2012. Buat Sendiri Aplikasi Petamu Menggunakan CodeIgniter dan Google Maps API. Yogyakarta: CV.ANDI OFFSET.
[15] Supono dan Virdiandry Putratama.2016. Pemrograman Web dengan Menggunakan PHP dan FrameworkCodeigniter. Yogyakarta: Deepublisher. 